\title{
LIVING IN A
}

MULTIGENERATIONAL

HOUSEHOLD

PRE-COVID / MID-COVID

Using A.I. and Big Data to tap into the voice of $50+$ people in the U.S. to unveil insights around multigenerational living before and during COVID-19

Culturlntel $\left.\right|^{T M}$ innovative methodology unveils actionable insight by gathering, mining and analyzing the open-sourced,

Q. WHERE ARE THE CONVERSATIONS TAKING PLACE?

PRE-COVID 4M

Relevant digital conversations $50+$ people in the U.S. had about Multigenerational Living from February 1st, 2019 to February 29th, 2020

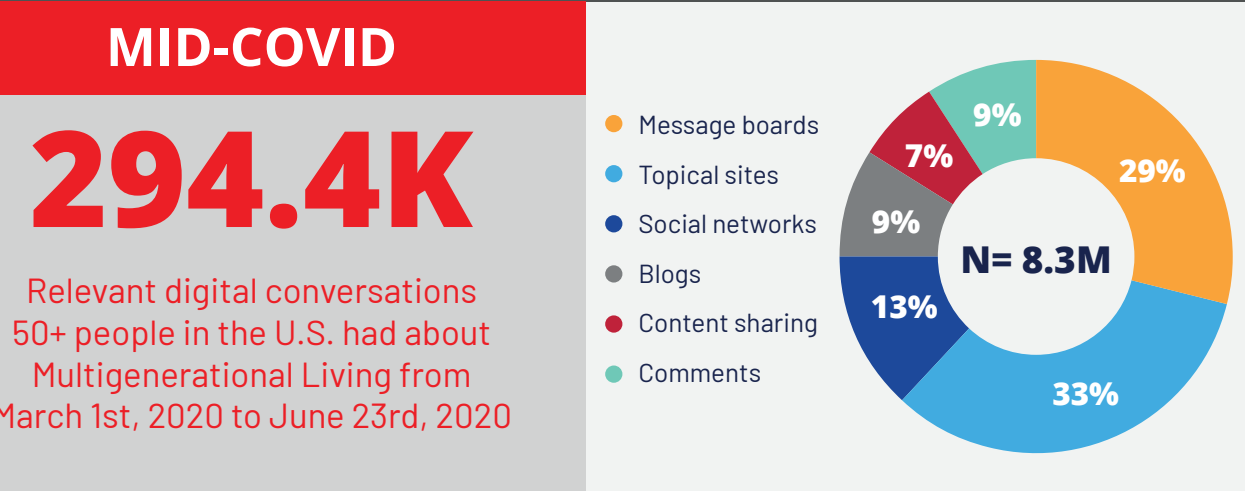

WHAT MOTIVATES 50+ PEOPLE TO LIVE WITH OTHER GENERATIONS?

Motivations for living in a multigenerational household: The reasons why people consider living in a multigenerational household. Motivations can be fueled by internal or external factors.

PRE-COVID, 50+ people were more motivated by love, by finding support/care and by survival than the overall population. During the pandemic they were still motivated by support and care, but they were also more motivated by obligations. probably towards their children who may have had to move back in with them.

PRE-COVID

MID-COVID

$43 \%$

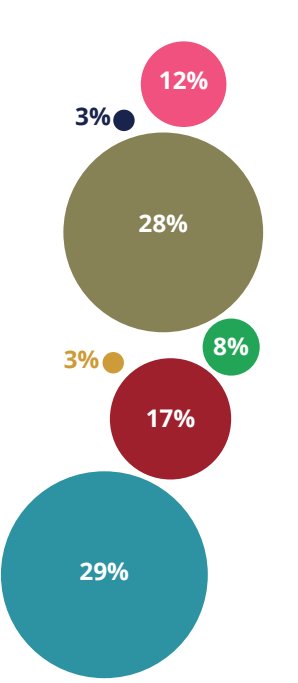

INTERNAL MOTIVES

Love/connection

Quality of life

Support/care

Obligation

Preparation

Recover

Survival

EXTERNAL MOTIVES

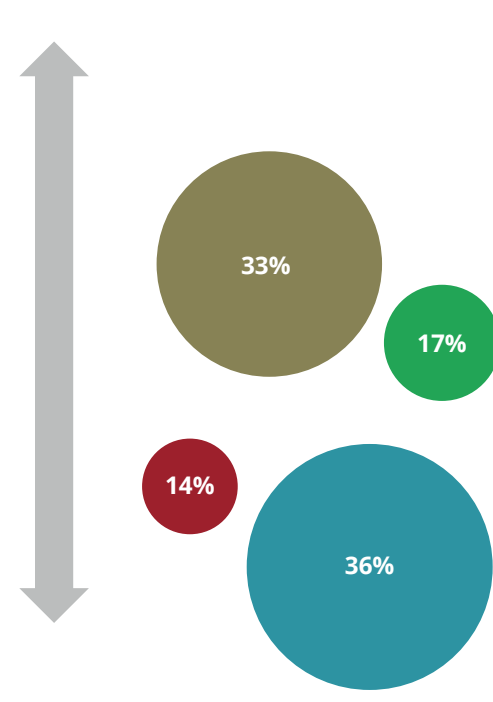

$33 \%$

$50 \%$

WHAT IS THE SENTIMENT OF 50+ LIVING IN MULTIGENERATIONAL HOUSEHOLDS?

Driving positive sentiments are perceived benefits, and driving negative sentiments are pain points associated with living in a multigenerational household.

Pre COVID-19, the main drivers for 50+ people were seeking the help they need and having a beneficicil financial arrangement. Social stigma was not a significant barrier, but they did face an emotional toll. During the pandemic, they have seen a drast
in the positive sentiment just like Overall, especially because they are feeling the inconveniences of living with others.

PRE-COVID

MID-COVID

\section{POSITIVE DRIVERS}

$29 \%$ Help or Support They are a great help having them 28\% Financial Advantage $13 \%$ Sharing Different POV 13\% Improved Lifestyle

23\% Emotional Toll "It can be extremely irritating at times" $18 \%$ Dependency "I'm afraid they will never be able
to make it on their own"

14\% Burden/Inconvenience/Crowding

$14 \%$ Personalities Discord

$11 \%$ Roles/Responsibilities

$11 \%$ Lack of Privacy

$9 \%$ Social Stigma

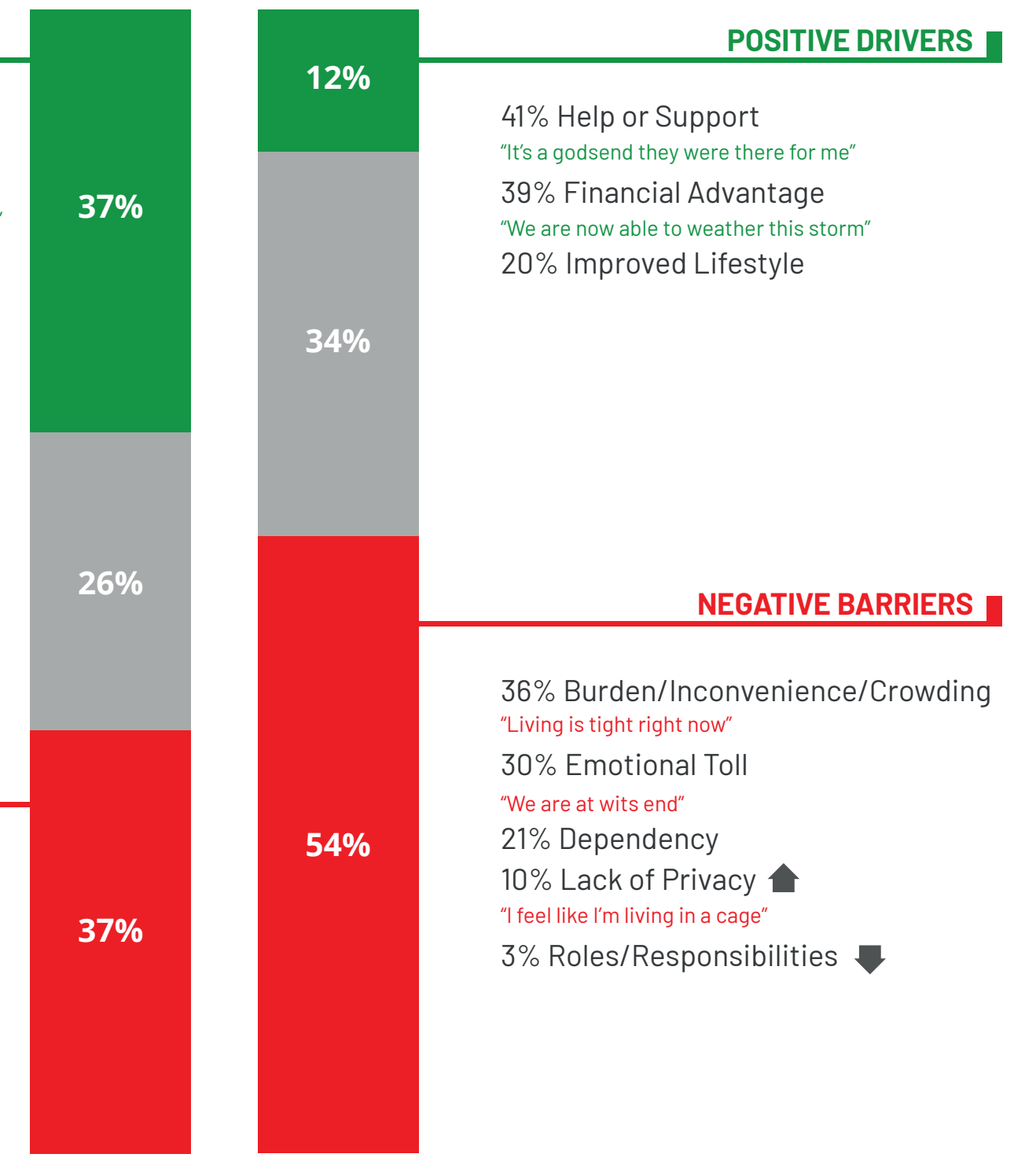

VARIATIONS AgAINST OVERALL AUDIENCE

Access the full report at www.aarp.org/multigenhome2020

KEY CONTACT: Joanne Binette, jbinette@aarp.org, AARP Research

Stephanie Firestone, sfirestone 